\title{
ICT FROM THE BOTTOM OF THE PYRAMID: DESIGN AND/OR DE-CONSTRUCTION?
}

\author{
Rocío Rueda Ortiz, Henrik Herlau and Leif Bloch Rasmussen \\ Rueda Ortiz is with the University of Colombia, Bogota, and Herlau and Rasmussen are with \\ the Copenhagen Business School, Denmark
}

Abstract: This paper reflects and calls for action on the possibility of using Information and Communication Technologies at the Bottom of the Pyramid by turning the pyramid into a diamond of knowledge creation and knowledge sharing. It tries to show what is at the heart of the challenges that C.K. Prahalad suggests in his vision of the Fortune from the Bottom of the Pyramid. Then it searches a theoretical basis of his claims in Transaction Cost Theory. However Transaction Cost Theory may itself be challenged using the theory of Max Boisot on Information Space and Social Learning, where data is taken to be a productive force along with labor and capital. The potential in the development of a better theory may then be formulated based on economizing on data. Knowledge creation and knowledge sharing at the bottom of the pyramid turns out to be the essence of what the design of ICT may contribute to a landscape of fair globalization. The role of ICT is taking to be support and enhancement of a balance between three forces Information Space and Social Learning: power, culture and knowledge. Finally it suggests a further meandering by a reflection on the need for the de-construction of Western thinking on economy, technology and knowledge.

\section{INTRODUCTION}

Through the history of mankind we have seen transitions from agricultural and industrial époques taking place in different cultures at different times. At the present day there are signs of a transition into a new époque, which in Western Cultures are labelled under different headings like: information society, bio-society, knowledge society, global society. In other cultures the headings might be - and maybe should be - different. 
In a paper with Stu Hart from 2002 and a book from 2005 C.K. Prahalad (Hart and Prahalad, 2002; Prahalad, 2005) asks the question: "What are we doing about the poorest people around the world? Why is it that with all our technology, managerial know-how, and investment capacity, we are unable to make even a minor contribution to the problem of pervasive global poverty and disenfranchisement? Why can't we create inclusive capitalism?"

These questions are not new at all, of course. They also are fundamental to questions of a similar kind in other areas as described in the 1970'ties by Hasan Ozbekhan (1976) as "La problématique"; i.e. "population explosion", "urban spread, or blight", "illiteracy", "hunger", "environmental deterioration", "energy shortage", "inflation", "pollution", "alienation", "dehumanization". Of course we may safely say: We do KNOW!

Thus in order to do something about it Stuart Hart and C.K. Prahalad wrote their paper on Strategies for the Bottom of the Pyramid. Their main point was - and is - that doing more of the same from the past would not help - history has shown that. In stead they suggested "... new and creative approaches are needed to convert poverty into an opportunity for all concerned. That is the challenge." (Hart \& Prahalad, 2002)

However, Prahalad writes in 2005: "Needless to say, not a single journal would accept the article for publication. It was too radical. Reviewers thought that it did not follow the work of developmental economics."

Leaders and MBA students took up the challenges raised in the paper when Hart \& Prahalad "published" the article on the WEB. Someone was listening in information space.

In another field of "La problématique" other people are working. Fair Globalization has turned out to be the term developed by ILO/UN as a way of handling questions on globalization through labor markets. In a third field of "La problématique" the idea of Fair Trade seems to transform itself into a movement where consumers and producers create alliances based on "commercial" community interests.

Other themes, other networks are created, and they all aim at a kind of community based self-organizing world of heterarchies challenging the well established "wisdom" of economics. 
This paper takes the challenges of "La problematique" and the relevance of Hart \& Prahalad's challenges for granted and the need for radical new and creative approaches to convert "La problématique" into an opportunity for all concerned individuals and communities.

The paper is by nature created as a bricolage. This means that the ideas in the paper are taken from many different sources not necessarily compatible with each other - but they are taken to be able to expand each other's mental horizon.

First we try to show what is at the heart of the challenges that Hart \& Prahalad suggest as expressed by Prahalad in The Fortune from the Bottom of the Pyramid (2005). Then we search for a theoretical basis for his claims in Transaction Cost Theory (TCT). However TCT may itself be challenged which we show by using the theory of Max Boisot on Information Space using data as a productive force along with labour and capital. The potential development of a better theory may then be formulated based on a political theory of economizing on data in which ICT may play a crucial role. Finally we suggest a further meandering by inquiring into the need for a deconstruction of Western historical thinking and theories in economics and technology.

\section{THE VISION OF PRAHALAD: THE FORTUNE FROM THE BOTTOM OF THE PYRAMID}

Prahalad starts with an expression of a dominant cultural logic of the West and a potential manifest for development through social transformations. He writes (Prahalad, 2005, p. xi, p. xiii and p. 2):

"We have to learn from the successes and failures of the past; the promises made and not fulfilled. Doing more of the same, by refining the solutions of the past - development aid, subsidies, governmental support, localized nongovernmental organizations (NGO)-based solutions, exclusive reliance on deregulation and privatization of public assets - is important and has a role to play, but has not redressed the problem of poverty.

The problem of poverty must force us to innovate, not claim "rights to impose our solutions" as the language we use may not be adequate.

The vision that is presented is the co-creation of a solution to the problem of poverty. The opportunities at the Bottom of the Pyramid (BOP) cannot be 
unlocked if large and small firms, governments, civil society, organizations, development agencies, and the poor themselves do not work together with a shared agenda. Entrepreneurship on a massive scale is the key. This approach will challenge the prejudices about the "role and value added" of each group and its role in the economic development at the BOP."

Though Prahalad's focus is on the role of the private sector it is obvious that the collaboration across various groups will be at the heart of the approach. This seems fine enough and the evidence from cases told by Prahalad are convincing, but we want none the less to inquire whether the hypothesis and suggestions for action are valid theoretically in order to avoid embarking in experiments and/or use of resources in creating empirical evidence. In short we search for a possible theoretical basis of the hypothesis.

\subsection{Dominant Logic of Western Thinking}

Prahalad tells us that the nature of the BOP market has characteristics that are distinct. And he tells us that some market development imperative must be followed. He lists the following distinct characteristics of the nature of the BOP market:

There Is Money at the BOP: The dominant assumption is that the poor have no purchasing power and therefore do not represent a viable market.

Access to BOP Markets: The dominant assumption is that distribution access to the BOP markets is very difficult and therefore represents a major impediment for the participation of large firms and MNCs.

The BOP Markets Are Brand-Conscious: The dominant assumption is that the poor are not brand-conscious. On the contrary, the poor are very brand-conscious. They are extremely value-conscious by necessity.

The BOP Market is Connected: Contrary to the popular view, BOP consumers are getting connected and networked. They are rapidly exploiting the benefits of information networks

BOP Consumers Accept Advanced Technology Readily: Contrary to popular belief, the BOP consumers accept advanced technology readily.

Then he lists the following imperative for the BOP market: 
Create the capacity to Consume: To convert the BOP into a consumer market, we have to create the capacity to consume. Cash-poor and with a low level income, the BOP consumer has to be accessed differently.

The Need for New Goods and Services: The involvement of the private sector at the BOP can provide opportunities for the development of new products and services.

Dignity and Choice: When the poor are converted into consumers, they get more than access to products and services. They acquire the dignity of attention and choices from the private sector that were previously reserved for the middle class and rich.

Trust Is a Prerequisite: Both sides - the large firm and the BOP consumer - have traditionally not trusted each other. The mistrust runs deep. However, private-sector firms approaching the BOP markets must focus on building trust between themselves and the consumers.

The dominant cultural logic then can be told like this (Hart and Prahalad, 2002):

\begin{tabular}{|l|l|}
\hline \multicolumn{1}{|c|}{ Assumption } & \multicolumn{1}{c|}{ Implication } \\
\hline $\begin{array}{l}\text { The poor are not target customers; } \\
\text { they cannot afford our products or } \\
\text { services }\end{array}$ & $\begin{array}{l}\text { Our cost structure is a given; with our } \\
\text { cost structure, we cannot serve the } \\
\text { BOP market }\end{array}$ \\
\hline $\begin{array}{l}\text { The poor do not have use for } \\
\text { products sold in developed countries }\end{array}$ & $\begin{array}{l}\text { We are committed to a form over } \\
\text { functionality. The poor might need } \\
\text { sanitation, but can't afford detergents } \\
\text { in formats we offer. Therefore, there } \\
\text { is no market in BOP. }\end{array}$ \\
\hline $\begin{array}{l}\text { Only developed countries appreciate } \\
\text { and pay for technological innovations }\end{array}$ & $\begin{array}{l}\text { The BOP does not need advanced } \\
\text { technology solutions; they will not } \\
\text { pay for them. Therefore, the BOP } \\
\text { cannot be a source of innovations. }\end{array}$ \\
\hline $\begin{array}{l}\text { The BOP market is not critical for } \\
\text { long-term growth and vitality of } \\
\text { MNCs }\end{array}$ & $\begin{array}{l}\text { BOP markets are at best an attractive } \\
\text { distraction. }\end{array}$ \\
\hline $\begin{array}{l}\text { Intellectual excitements is in } \\
\text { developed markets; it is very hard to } \\
\text { recruit managers for BOP markets. }\end{array}$ & $\begin{array}{l}\text { We cannot assign our best people to } \\
\text { work on market development in BOP } \\
\text { markets }\end{array}$ \\
\hline
\end{tabular}


Finally Prahalad suggests that another cultural logic could be told by changing the Pyramid into a Diamond through "development as social transformation" using the following ideas:

- Breaking down barriers to Communication

- BOP Consumers Upgrade

- Gaining Access to Knowledge

- Identity for the Individual

- Women Are Critical for Development

- Evolving Checks and Balances

The real test, he says, would be to show that the Pyramid could be the changed into a Diamond like the illustration on page 110:
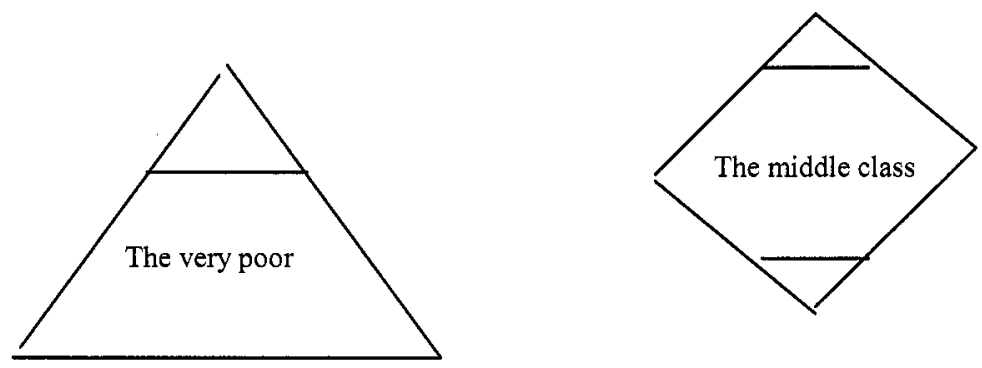

\section{IN SEARCH OF THEORETICAL BASIS TRANSACTION COST THEORY (TCT)}

In order to have a better understanding of the suggestions of Prahalad and thus suggestions for ICT as enabler of the Fortune from the BOP we need to dig a little deeper than done by Prahalad. Maybe and maybe not we are right, but it is our hypothesis that Prahalad bases his calling for the BOP market on a way of using the transaction cost theory. At least his heavy reliance on economic and cultural measures like Self Helping Groups (SHGs), local public e-service shops and Transaction Governance Capacity (TGC) in combination with innovative use of ICT points in that direction. 
We suggest that this challenge is based on the theories of - among others - the Nobel Laureates Ronald Coase, John Nash, Douglas North and Joseph Stiglitz:

Either to minimize transaction costs in business by externalizing and sharing these costs through cooperative networks based on mutual trust, or to minimize transaction costs by internalizing these costs through hierarchies based on competition.

\section{Some definitions}

Transaction: A transaction is an economic exchange, the transfer of some good or service between technologically separable activities. The transaction is regarded by transaction cost economics as the fundamental unit of investigation. The rules and institutions governing a particular transaction constitute its governance structure, and the task of transaction cost economics is to determine, for a particular transaction, the most efficient (production and transaction cost minimizing) governance structure from a list of those available.

Transaction costs: Transaction costs are the costs of administering an exchange relationship. These include the costs of negotiating, drafting, and monitoring contracts; the costs of settling disputes and enforcing settlements; and the opportunity costs associated with administering a contract inefficiently until a new agreement is recognized as necessary and then reached.

New Institutional Economics: applying economic theory and quantitative methods in order to explain economic and institutional change.

Prahalad seems to believe that the "market" can take care of the poor (however defined), supported by Transaction Cost Governance, i.e. by some kind of bureaucracy. But in what way does he define market? Is it a market of capital, labour, goods and services or a market of information/knowledge? Are the rules of the game the same in economizing on labour and capital as in economizing on information/data? And is it a necessity to use the rules of the market (the invisible hand, free market, protectionism, fair trade) by Developing Countries in order to follow the same historical track of growing BNP as suggested by neo-liberal economics? Protected or secured by a sort of benevolent bureaucracy in the words of Prahalad: Transaction Cost Governance? 
However Coase - the founder of the theory in his Nobel Prize speech in 1991 expresses the need for much more work on the theory and the experimental evidence needed. Coase tells it this way in his Nobel lecture (Coase, 1991):

"Oliver Williamson has ascribed the non-use or limited use of my thesis in The Nature of the Firm to the fact that it has not been made "operational", by which he means that the concept of transaction costs has not been incorporated into a general theory. I think this is correct. There have been two reasons for this. First, incorporating transaction costs into standard economic theory which has been based on the assumption that they are zero, would be very difficult and economists who, like most scientists, as Thomas Kuhn has told us, are extremely conservative in their methods, have not been inclined to attempt it. Second, Williamson has also pointed out that although I was correct in making the choice between organization within the firm or through the market the center piece of my analysis, I did not indicate what the factors were that determined the outcome of this choice and thus made it difficult for others to build on what is often described as a "fundamental insight". This also is true. But the interrelationships which govern the mix of market and hierarchy, to use Williamson's terms, are extremely complex and in our present state of ignorance it will not be easy to discover what these factors are. What we need is more empirical work. In a paper written for a conference of the National Bureau of Economic Research. I explained why I thought this was so. This is what I said: "An inspired theoretician might do as well without such empirical work, but my own feeling is that the inspiration is most likely to come through the stimulus provided by the patterns, puzzles and anomalies revealed by the systematic gathering of data, particularly when the prime need is to break our existing habits of thought". This statement was made in 1970. I still think that in essentials it is true today. Although much interesting and important research was done in the seventies and eighties and we certainly know much more than we did in 1970, there is little doubt that a great deal more empirical work is needed. However, I have come to the conclusion that the main obstacle faced by researchers in industrial organization is the lack of available data on contracts and the activities of firms. I have therefore decided to do something about it. 
My remarks have sometimes been interpreted as implying that I am hostile to the mathematization of economic theory. This is untrue. Indeed, once we begin to uncover the real factors affecting the performance of the economic system, the complicated interrelations between them will clearly necessitate a mathematical treatment, as in the natural sciences, and economists like myself, who write in prose, will take their bow. May be this period soon come.

I am very much aware that many economists whom I respect and admire will not agree with the opinions I have expressed and some may even be offended by them. But a scholar must be content with the knowledge that what is false in what he says will soon be exposed and, as for what is true, he can count on ultimately seeing it accepted, if only he lives long enough."

Thus Coase himself finds reason for being careful in applying TCT. It is our suggestion that that caring may be taken from a theory developed by Max Boisot, i.e. economizing on data, information and knowledge as a way of minimizing transaction costs.

\section{BOISOT'S VISION ON ECONOMIZING ON LABOUR, CAPITAL AND DATA}

Boisot $(1995,1998)$ uses an approach starting by viewing data as part of an evolutionary production function. Then he shows how data may be turned into knowledge using social learning supported and enhanced by culture (institutions), competencies development and technology, especially ITC. In order to do that he suggests a radical development of the TCT as that theory is taken to be too one-dimensional in its choice on internalizing or externalizing transaction costs.

\subsection{Data as a Production Force}

In Information Space (1995) Max Boisot suggested that data may be taken to be like labor and capital in a production function. This means that the traditional production function in a two-dimensional space must be expanded to a three-dimensional space, where the level of production (the isoquant) is taken to be a function of labor, capital and data. Using ordinary thinking on minimizing effort in production we then have three factors to 
minimize. Then the hypothesis is that the neo-classical theory of economics is economizing on labour and capital in two ways:

- Substitution of labour for capital and vice versa

- Jumps towards zero effort (presumably through knowledge and technology)

Boisot suggests that these ways must be supplemented by ways of economizing on data. He does this by joining Capital and Labour into Physical Resources and combine them with data. Then the production function may be shown like this.

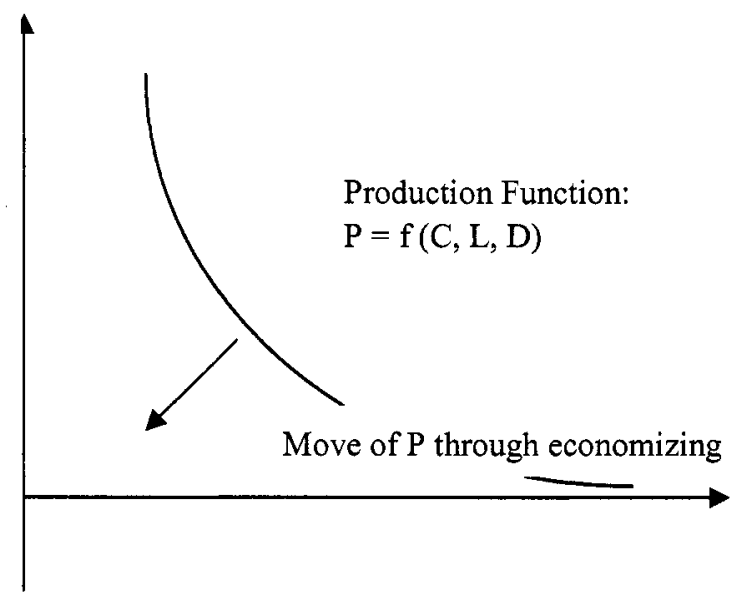

Physical

(Naturally this image of the production function should be threedimensional, but we keep it in two-dimensions for simplicity).

But the question then is: What are the content of the "data" dimension? Boisot suggests that there are three dimensions in economizing on data (which must be seen along with the more traditional economizing on capital and labour):

Coding - naming reality

Abstraction - making models of the world

Diffusion - distributing data/information/knowledge 
Together these three dimensions creates an Information Space (I-Space) and can be shown like this:

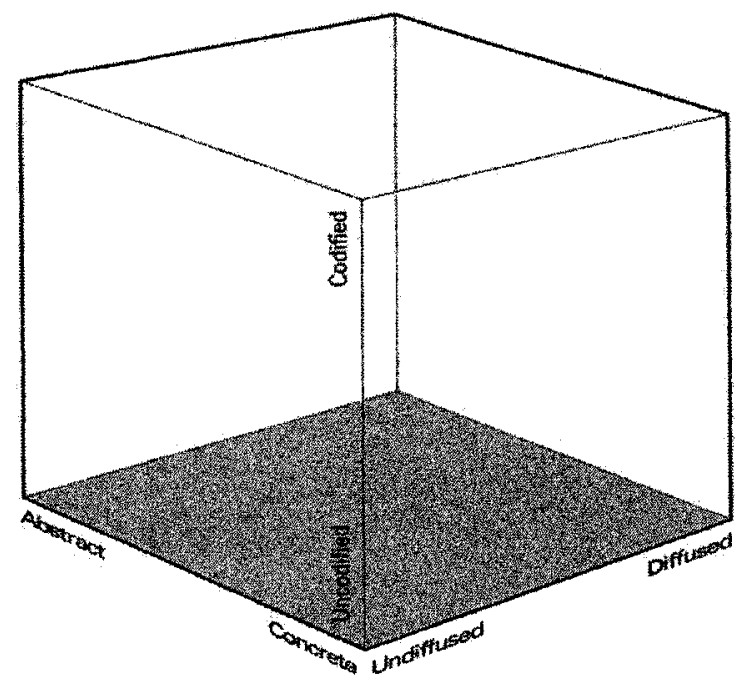

The Information Space

The content of the I-space can be interpreted in three interacting spaces:

\section{Epistemological Space:}

Coding

\begin{tabular}{|c|c|}
\hline $\begin{array}{c}\text { Technical } \\
\text { knowledge }\end{array}$ & $\begin{array}{c}\text { Scientific } \\
\text { knowledge }\end{array}$ \\
\hline $\begin{array}{c}\text { Aesthetical } \\
\text { knowledge }\end{array}$ & $\begin{array}{c}\text { Craft } \\
\text { knowledge }\end{array}$ \\
\hline
\end{tabular}

Abstraction

Cultural Space:

Coding

\begin{tabular}{|c|c|}
\hline $\begin{array}{c}\text { Property } \\
\text { knowledge }\end{array}$ & $\begin{array}{c}\text { Public } \\
\text { knowledge }\end{array}$ \\
\hline $\begin{array}{c}\text { Personal } \\
\text { knowledge }\end{array}$ & $\begin{array}{c}\text { Common- } \\
\text { sense } \\
\text { knowledge }\end{array}$ \\
\hline
\end{tabular}

Diffusion 


\section{Utility Space:}

Abstraction \begin{tabular}{|c|c|}
\hline $\begin{array}{c}\text { Esoteric } \\
\text { knowledge }\end{array}$ & $\begin{array}{c}\text { Global } \\
\text { knowledge } \\
\text { Local } \\
\text { knowledge }\end{array}$ \\
\hline $\begin{array}{c}\text { Topical } \\
\text { knowledge }\end{array}$ \\
\hline
\end{tabular}

Then value - the creation, sharing and using of knowledge in the production function - is created by movement in the I-Space through six phases by effectively activating all parts of the I-Space. This curve is called the Social Learning Curve (SLC).

The six phases in SLC are as follows:

Scanning: Identifying threats and opportunities; patterns and insights.

Problem-solving: creating structure out of the identified elements of data/information. Reduces uncertainty and challenges existing knowledge.

Abstraction: Generalization of obtained structure of data/information.

Diffusion: Sharing obtained knowledge with target groups.

Absorption: New knowledge being absorbed and made tacit, bodily. Learningby-doing.

Impacting: Embedding knowledge in praxis, in products, techniques, behaviour.

The model shown here are the ideal as seen by Boisot. In reality, of course, it may take many forms.
The Information Space

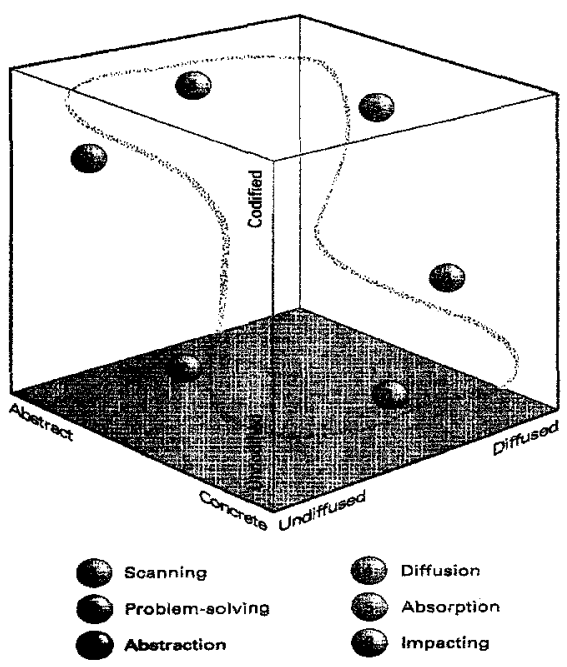

The Social Learaing Cycle (SLC) 
Boisot uses the metaphor of data being scattered (centripetal force) or gathered (centrifugal force) in an electro-magnetic field and then turned into information and knowledge according to social learning, culture, institution building, competencies and technology.

\subsection{Transaction Costs and Information Space}

Boisot interprets the concept of transaction as follows (Knowledge Assets, 1998, p. 124):

"Following the lead given by new institutional economics, we shall take the transaction as our unit of analysis. For our purposes, a transaction can be thought of as any act of social exchange that depends on information flows for its accomplishment. Transactions can be as simple and brief as the purchase of a packet of cigarettes, or as complex as and extended as those which bind a Zen master to his disciples. Like institutional economists, we are interested in the relationship that can be established between different transactional characteristics and the phenomenon of institutionalization. Our use of the term transaction, however, will extend beyond that of institutional economics where the focus has tended to be primarily on transaction costs and efficiency considerations. These, to be sure, are relevant. But, as we shall see, they are not the whole story."

In this critique of the use of transaction cost theory and new institutional economics Boisot tries to keep both the cake and the penny (Boisot, 1995, p. 235):

"To summarize, the production of information and its use in transactions both incur costs and are thus subject to economizing. In the 1970s, there occurred a revival of interest among economists in the economics of transaction, and Oliver Williamson in particular, building on the earlier work of Ronald Coase and John Commons, has explored the different institutional arrangements that govern transactional choices. ... we shall also concern ourselves with the institutional order built up from transactions, but our focus will be less narrowly economic than the one adopted by Williamson. Like him, we shall argue that institutional structures aim partly at achieving transactional efficiencies and that where such efficiencies are effectively achieved they act somewhat like a magnetic field - a mathematician would call them 'attractors' - drawing the uncommitted transaction into a given institutional orbit. Yet in contrast to Williamson's, our concept of transactions is underpinned by an explicit rather than an implicit theory of information production and exchange which yields a different way of classifying them as well as a 
distinctive approach to their governance. We find ourselves in consequence in the realm of political economy rather than of economics tout court."

The first step in doing so is to establish a link between institutional economics and cultural analysis as institutions may be taken to be crystallized out of transactional structures mediating a cultural order or mediated by culture.

The problems ahead of us must be a discussion on the differences between the approach to transactions outlined in the Information Space theory and that adopted by the new institutional economists such as Oliver Williamson. The differences are numerous but the most important according to Boisot are (Information Space, 1995, p. 288-290):

1. Only information diffusion is brought into focus in NIE [New Institutional Economy], not coding and abstraction ... for which NIE uses terms like 'uncertainty' and 'atmosphere'. Much transactional richness relates to codification and abstraction and escapes such formulations/terms.

2. The markets and hierarchies paradigm implies, but does not develop a dynamic theory of information flows ... NIE uses terms like "information impacting', 'opportunism' and 'strategic behaviour' in service of a static theory of transactional assignment.

3. In the absence of a conceptual scheme that could factor out governance issues from transactional ones, the new institutional economists have tended to conflate the two: hierarchies are treated as a matter of course as internal to firms, and markets as institutions that are external to firms. Hybrid forms, to be sure, exist between these polar alternatives, and in such cases one talks of bilateral governance.

Institutional economics thus is part of the way forward, but not the only way (Boisot, 1995, p.290-1):

"In spite of such limitations, the New Institutional Economics research programme, given its willingness to acknowledge the central role played by information in the economic process, constitutes a marked advance over what is on offer from the neoclassical orthodoxy. There, information retains the status of the luminiferous ether of classical physics before Einstein: a ubiquitous medium that admitted of a mechanical account of action at a distance and kept the world conveniently Newtonian. 
Institutional economics, however, needs a more explicit and dynamic theory of information flows if it is to make more than a dent in the neoclassical defences. Having established that there exists credible institutional alternatives to markets, it needs to show how information production and exchange underpins them all, shaping their internal evolution as well as how they collaborate and compete. In effect, what is needed is a theory of social learning that extends beyond the individual or the organization to encompass more complex institutional settings. Such as theory, I believe, is foreshadowed in Douglas North's historical studies of institutions. It now needs further development."

Thus we may join forces with Boisot and start inquiring into the ways of using this new theory at the Bottom of the Pyramid. Economizing information costs in its own terms in creation, sharing, using and destroying knowledge through the Social Learning Curve is not the only way of economizing. Culture, individual and collective competencies development and ICT may be designed to take part in that economizing.

\subsection{Culture as economizing}

Transactions floating around in the I-Space may then be hypothesized as being attracted to each other under the influence of the culture, that so to speak create an electro-magnetic field of attraction in and around the ISpace. Accordingly institutions are built in order to facilitate particular kinds of transactions - in order to minimize costs. In the upper left corner transactions will be build around highly coded and abstract data, where bureaucracies are able to handle the data as they involve explicit information like copyrights, contracts, patents, rule, laws, regulations and procedures. In the upper right corner such data can be distributed more easily to many people along the diffusion scale, as explicit knowledge are more easily distributed using media than implicit, tacit knowledge.

In the lower regions of the I-Space institutions take the form of fiefs (in the lower left region) and clans (in the lower right region) depending on how many people are involved and whether the transactions functions in hierarchies or non-hierarchies. In these regions the transactions are based on personal contacts and shared values and beliefs.

There is strong evidence that national cultures and institutions play a part in predisposing firms to transact from a given region of the I-Space. Boisot suggests that 
- The Anglo-Saxon culture with its strong preference for competitively determined contractual relations will prefer market based transaction

- The Latin-American culture are more committed to the role of the state and bureaucracies

- Chinese and Japanese culture will be much more personalized and committed to informal and tacit forms of exchange of data/information, the difference being that Japanese culture are less centralized than Chinese culture.

Different patterns of data may arise bringing all possibilities into play as culture shapes institutions as strong attractors for data. Again using the metaphor of an electro-magnetic field: Quite distinctive cultures manage to

"... confine the larger part of their transacting to a particular region in the space. If the institutions of Marxism-Leninism, for example, tried to restrict the economic and social transactions of the planned economy to the bureaucratic region of the I-Space those of Thatcherism, by contracts attempted to channel what many would consider to be non-economic transactions towards the market region of the space. In each case a distinctive culture was aimed for, one in which ideology was in the drivers seat. Ideology, by legitimating transactional assignments on other grounds than their own merit, can render a given region of the I-Space at least temporarily - almost impervious to transactional competition from other regions." (Boisot, 1998, p. 143)

Boisot $(1998$, p. 151) then concludes on economizing by culture:

"At the level of firms, therefore, only those whose cultural repertoire gives them transactional capacity throughout the I-Space can summon and adequate learning response to any emerging gaps between technology and culture. Those operating from too narrow a cultural base in the space, however, must of necessity lose control of the SLC unless they can complement their limited cultural repertoire through carefully selected interfirm and intercultural collaborations - i.e. through an externalization of transactions that link them with agents located elsewhere in the space. However, they will then confront the same problems of integration that more culturally diverse firms encounter inside their organization when trying to coordinate the activities of different functions or businesses. There is no cheap grace."

Related to the issue of ICT we may safely say that ICT should be used for enhancing diversity of cultures and their joint cooperation. 


\subsection{Competencies and Economizing}

The main idea behind bringing competencies into play in the I-Space and the SLC is related to a question of creating and maintaining corecompetencies as a strategic competitive (or shouldn't we say cooperative) advantage for a nation, a region or a company.

Boisot is rather critical towards the concept of core competence as it is described by Hamel and Prahalad (1989). They see a core competence to be unique to a firm and largely tacit and hard to imitate. In their view the only strategic relevance of a core competence is the possibility to exploit it in value adding. That can only take place in the upper part of the I-Space. But core competencies need to be coded and abstracted and then put into patents, contracts, property rights etc. In short made scarce, a process Boisot calls knowledge hoarding in contrast to what he takes to be a better road: knowledge sharing.

Boisot sees this other way of development and use of core competencies as a way of handling complexity. He explains (Boisot, 1998, p. 205):

"... it makes sense to describe a core competence as a complex adaptive system, located in the lower regions of the I-Space between an ordered regime in which knowledge assets get frozen into technologies and a chaotic regime in which the stability necessary for effective organizational coordination and integration remains absent. Core competences, then, have their being in a region of the I-Space sandwiched between an excess of usable structure and a total lack of it.

We hypothesize that the possession of a core competence is one measure of a firm's ability to deal with complexity."

It is difficult to keep a balance between drifting to the bureaucracy part of the I-space trying to make the core competence explicit in order to get organized and re-engineer efforts for competitiveness and letting the entrepreneurial spirit flourish.

However we might conclude with Boisot (Boisot, 1998, p. 205):

"Only firms that can handle a full SLC, together with the multiple cultures required to drive it, will be able to cope with the many and conflicting demands of a complex regime. 
We know from section 1.4 that complex structures operate at a higher level of entropy than more traditional and ordered structures, and that their effective management requires greater data-processing capacities. It follows that firms which operate in the complex regime in the I-Space will need different data-processing strategies than firms that do not."

Thus it is of the greatest interest too inquire into what way ICT may affect a firm's, a region's and a nations - a culture's - choice of dataprocessing strategies, which is the same as asking for ways of handling knowledge assets.

\subsection{ICT and Transactions in I-Space.}

The overall idea of working on strategies for ICT will then be at least three-fold:

1. In order to be innovative and develop new core competences ICT may be strategically used to move the SLC towards the right and to the bottom of the I-Space

2. In order to handle diversity in SLC's, competencies, cultures and institutions ICT may be strategically used to link and support this diversity.

3. In order to support a variety of cultural logics other means of economizing on data than ICT should be in focus of our social and spiritual awareness, especially inquiring relations among social partners.

\section{SOCIAL DIALOGUE AND INFORMATION SPACE}

Putting these ways of economizing on data together must call for the participation of the Bottom of the Pyramid, as it is there uncoded and concrete data exist. This call is radical in two ways: (1) it calls for ways of getting the BOP to take part in the knowledge based economy (that is the radicality of Prahalad), and (2) it calls for a political information economy in which the potential wealth created by knowledge sharing are also shared.

As Boisot explains in Information Space (Boisot, 1995, p. 330):

"A cultural pattern in the I-space becomes internally consistent and stable when its constituent institutional linkages and related transactional investments are mutually reinforcing and any antagonist linkages that might emerge are suppressed. Drawing on the connectionist perspective 
developed in Chapter 2 with its emphasis on excitatory and inhibitory linkages in neural activation patterns, one might even in such a case speak of a cultural logic in which different parts of the transactional structure are either jointly activated or mutually exclusive. Where such a logic consistently favours the activation of a particular pattern, whether centripetal or centrifugal, one might then speak of a cultural order. The pattern thus favoured may act as an attractor for a particular region of the I-space. For example, a capitalist order is generally thought of as a cultural pattern of transactions that is centrifugally spread out throughout the I-space but whose overall logic is designed to protect and enhance the transactional viability of the market region; a feudal order generates a cultural logic that aims to achieve the same for the fief region, and so on.

A cultural logic may survive the generative or destructive effects of the SLC by shifting to new institutions as they emerge in the I-space, selecting these on the basis of their pattern-preserving properties. It may thus exhibit what Ross Ashby calls ultra-stability."

In the two books of Boisot on which we have based our arguments a conclusion on the design of ICT-systems may be drawn:

Boisot concludes in Knowledge Assets (Boisot, 1998, p. 270-1):

"Putting a political economy of information on the agenda will require academics, managers, and policy-makers to address issues such as the following:

Institutional issues: How does the assumption that the world is for the most part nonlinear modify the nature of institution building?

Organizational issues: How does the 'virtuality' of organizations affect their governance?

Accounting issues: What impact will the shift form energy-based assets to knowledge assets have on accounting practices?

Educational issues: What educational practices best equip agents successfully to manage the six steps of an SLC on a lifetime basis?

Employment issues: what kind of employment policies would make creative destruction less threatening and yet productive.

Political issues: How will nation-states maintain sovereign control over knowledge-based economic activities that have no identifiable spatio-temporal location?

The conclusion of Boisot in Information Space, (Boisot, 1995, p. 356): 
"The real contest, from the perspective we have adapted, is not between the ideology of markets and that of hierarchies as alternative ordering principles for economic action but between a centripetal and a centrifugal cultural - and hence economic - order. And since, according to our analysis, only the first can properly be called ideological, this contest cannot be framed as one between competing ideologies. Rather it has to be seen as one between an ideological and evolutionary order. It effectively reaffirms the distinction that Popper has already made between a closed and an open society, but it does so this time on information grounds."

And there of course we start again with new hopes - as is always the case - in an inquiring mood:

1. Since theory building and testing is ultimately a collective enterprise, the hope is that those who have found the ideas presented in these pages of interest - practitioners as well as theoreticians - will help to address the above issues and place the evolving theory on a sounder footing. They can do this either by challenging what has been presented, or by building on it. In either case, doubtless, some rebuilding will be called for. Hopefully, however, the concepts presented in these pages will prove to be robust. This last paragraph is also a citation from Boisot (1998, p. 271)

2. The diamond may not only be found in a fair distribution of economic wealth. The diamond must also be found in a balancing of forces in autonomous, intensive and meaningful creation and sharing of knowledge.

3. That this calling may be put to the most severe test of falsification.

We strongly believe that Boisot has provided for the first of these three hopes. Using his theories on the vision of Prahalad we try (in chapter 6) to provide some guideline for the second hope. For the third hope we try (in chapter 7) to reflect on a possible de-construction of the language used thus far.

\section{THE REAL TEST REVISITED: A DIAMOND IN I- SPACE}

The social learning curve may be seen - however its form - as a way of bringing forces in minimizing information costs into play. This is done by bringing all types of transactions into play. That would be an ideal in a world where knowledge creation, knowledge sharing joins forces with a 
sustainable way of handling labor and capital, physical resources as they are summarized by Boisot.

Thus the diamond called for by Prahalad is only two-dimensional in the I-Space. This means that e-Governance for the poor in a knowledge based economy by necessity will be controlled by either the hierarchy/bureaucracy or the market. That is by those who are able to handle and control explicit knowing, in short cultures and institutions in the upper parts of the I-Space.

It will not be possible to include cultures and institutions in the lower parts of the I-Space. This means that the dichotomy implicit in Transaction Cost Theory between competitiveness and trust is false as it only takes place in the upper part of the I-Space where the rules of the game is power. Getting other parts of the I-Space included in minimizing information costs must include the lower parts, i.e. the dichotomy - or rather the dilemmas in choosing between power and trust!

One may say then - and act accordingly - that the new hypothesis for a theory on ICT from the Bottom of the Pyramid might be shown as a diamond inside the I-Space, where forces are kept in balance in three dimensions.

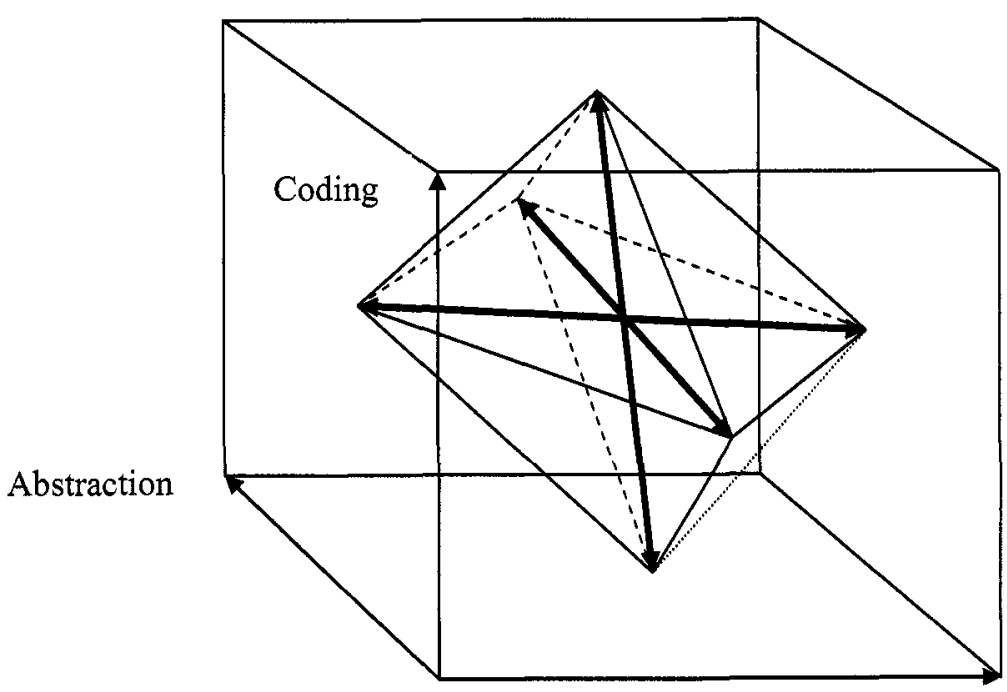

Diffusion 
Economize in the utility space (coding-diffusion): that would be a choice on internalizing or externalizing transaction costs based on political power, i.e. hoarding vs. sharing knowledge

Economize in the cultural space (abstraction-diffusion): that would be a choice on cultural diversified knowledge or cultural dominant knowledge, i.e. individualizing vs. socializing

Economize in the epistemological space (coding-abstraction): that would be a choice of generalized interdisciplinary knowledge or disciplinary knowledge; i.e. particularity vs. sensus communis

The three forces in I-space along with their relation to the threedimensional production function puts our ways of economizing on data to the real test:

How can we design ICT-landscapes in such a way that they support checks and balances of forces in I-Space?

How can we design ICT-systems that support and enhance the threedimensional production function for sustainability and fair globalization?

Having a map at one's disposal, however, does not necessarily make it safe and secure to choose a journey. It might depend on whether the map is taken to be showing a real or a virtual landscape worthwhile for designing our travel. So we need at least to reflect on a possible de-construction of the language in which the map has been created before we use it for the design of ICT-systems from the Bottom of the Pyramid.

\section{REFLECTIONS ON CONCEPTS OF MARKET, CONSUMERS AND POVERTY}

Jacques Derrida, in Specters of Marx (1998), claims "...that we are all in debt to Marxism as the New World Disorder crumbles.' A Spectre is haunting Europe the spectre of communism'. Challenge or invitation, "encouragement," seduction countering seduction, desire or war, love or hate, provocation of other ghosts: Marx insists on this a lot for there is $a$ multiple of this sociality. For if no use-value can in itself produce this mysticality or this spectral effect of the commodity, and if the secret is at the same time profound and superficial, opaque and transparent, a secret that is all the more secret in that no substantial essence hides behind it, it is because 
the effect is born of a relation (ferance, difference, reference, and diffarence), as double relation, one should say as double social bond.

This double socius binds on the one hand men to each other. It associates them insofar as they have been for all times interested in time, Marx notes right away, the time or the duration of labour, and this in all cultures and at all stages of techno-economic development. This socius, then, binds "men" who are first of all experiences of time, existences determined by this relation to time which itself would not be possible without surviving and returning, without that living present and being "out of joint" that dislocates the self-presence of the living present and installs thereby the relation to the other. The same socius, the same "social form" of the relation binds, on the other hand, commodity-things to each other. On the other band how? And how is what takes place on the one band among men, in their apprehension of time, explained by what takes place on the other hand among those spectres that are commodities? How do those whom one calls "men," living men, temporal and finite existences, become subjected, in their social relations, to these spectres that are relations, equally social relations among commodities?

If capitalization has no rigorous limit, it is also because it comes itself to be exceeded. But once the limits of phantasmagorization can no longer be controlled or fixed by the simple opposition of presence and absence, actuality and inactuality, sensuous and supersensible, another approach to differences must structure ("conceptually" and "really") the field that has thus been re-opened. Far from effacing differences and analytic determinations, this other logic calls for other concepts. One may hope it will allow for a more refined and more rigorous restructuring. It alone in any case can call for this constant restructuring, as elsewhere for the very progress of the critique.

But also at stake, indissociably, is the differential deployment of tekkne-, of techno-science or tele-technology. It obliges us more than ever to think the virtualisation of space and time, the possibility of virtual events whose movement and speed prohibit us more than ever (more and otherwise than ever, for this is not absolutely and thoroughly new) from opposing presence to its representation, "real time" to "deferred time," effectivity to its simulacrum, the living to the non-living, in short, the living to the livingdead of its ghosts. It obliges us to think, from there, another space for democracy. For democracy-to-come and thus for justice. We have suggested that the event we are prowling around here hesitates between the singular "who" of the ghost and the general "what" of the simulacrum. In the virtual 
space of all the teletechnosciences, in the general dis-location to which our time is destined - as are from now on the places of lovers, families, nations - the messianic trembles on the edge of this event itself. It is this hesitation, it has no other vibration, it does not "live" otherwise, but it would no longer be messianic if it stopped hesitating: how to give rise and to give place, still, to render it, this place, to render it habitable, but without killing the future in the name of old frontiers? Like those of the blood, nationalisms of native soil not only sow hatred, not only commit crimes, they have no future, they promise nothing even if, like stupidity or the unconscious, they hold fast to life. This messianic hesitation does not paralyse any decision, any affirmation, any responsibility. On the contrary, it grants them their elementary condition. It is their very experience.

The question deserves perhaps to be put the other way: Could one address oneself in general if already some ghost did not come back? If he loves justice at least, the "scholar" of the future, the "Intellectual" of tomorrow should learn it and from the ghost. He should learn to live by learning not how to make conversation with the ghost but how to talk with him, with her, how to let thus speak or how to give them back speech, even if it is in oneself, in the other, in the other in oneself: they are always there, spectres, even if they do not exist, even if they are no longer, even if they are not yet".

What does it mean to come back to the ghost of Marxism? Even accepting the distance and the critique of Marxism (by Marx) there is one basic idea left: social justice and communitarism. A debt from all the ghosts of our history and our past that we cannot forget. We need to live with them, learn from them and dream of other possible worlds.

But deconstruction means that we have to accept paradoxes. For instance, the paradox between the market as institution and the alternative forms of market (individuals or communitarian) that tries to do resistance to the global market and on consequence develop bottom-up processes. On the one hand we need to create institutional alternatives to markets that show how information production and exchange can be done by collaboration, but accepting conflict and antagonism as potential of the social relationships between global and local markets. On the other hand, we need a politics of trust or confidence in the market that encourage us to extend possibilities of action and experience. So the idea of one market, as institution, should leave part of initiative to an "other", should accept that the future can come from the action of an "other", implying the acceptance of the risk of renouncing 
partially to power and control, accepting a space of freedom where "the other" can be a singular subject or a singular community of subjects.

What does it mean try to change the pyramid? We can see some differances: as exclusion, and as inclusion. What is settled is that the global market in information society is creating a big difference between the regions which are subordinated, e.g., Africa, Latin America which are being excluded from the capital fluxes transported by ICT. That subordination is bound to the poverty conditions of regions and countries. In this case, inverting the pyramid has to be done through the incorporation of ICT to the production, as a way to inclusion. But differance also means postponement, delay, deferment. It is what Derrida called the differential deployment of tekkne. How are developing or subordinated counties deploying technologies? Which kind of technologies are being adopted by them? How are those technologies being involved in the social and productive world? And how are they changing societies and cultures?

Let us go one step ahead and then we will come back to Derrida, Marx and his ghosts. Negri (2003) shows that there are three kinds of tasks that lead the post-modern global economy:

- incorporated ICT in transforming the process of industrial production itself

- the "immaterial" work of creative and intelligent manipulation of symbols

- the "immaterial" work bounded to production and manipulation of affects and human contact (virtual or real), or corporal work

What we want to emphasize is that new ways of production (immaterial, computerized, ICT) has cooperation as its main characteristic. The immaterial work includes interactions and social cooperation. The difference with Marxist view of the economy is that the cooperative work is not imposed from the exterior, as it occurred in past forms of labour: no cooperation is completely immanent to the labour activity. This means that we can imagine that productivity and wealth can be acquired through a form of cooperative interactivity through linguistic, communicative and affective nets. In other words we can think (we can dream) that the new "immaterial work" could provide a potential for a kind of spontaneous and basic communism. Now the ghost of Marx has come again.

What cultural changes does this imply? If we accept the cooperative model of production, we have to see the possibility of creating markets 
organized in a horizontal net, challenging the power structures between regions (developed to developing countries) and even inside of each local or communitarian market. But we have to be alert because along with the global process of the information society there is also decentralization and dispersion that is provoking new ways of centralization and control of the production (as many mega corporations has shown us). So, the paradox is that we need a new model of production that can allow us to create flexible and cooperative nets, but the nets also are being designed and fixed for control. In political terms that mean that the global infrastructure of information has two main mechanisms of power: democracy and oligopoly. The democratic net is a model horizontal and without frontiers, without centre. The oligopoly model is a model where the production is centralized, the distribution is massive and the communication is only in one direction. This is a model in which most of the transnational corporations are interested, a model by which they want to establish and consolidate their monopolies in the new informational infrastructure.

But of course, we believe that the net is not just white or black. The information society is a hybrid of both models: democracy/oligopoly, horizontal/vertical relationships. And there are also portions of resistance but they have to fight without rest to keep their spaces of freedom and cooperation. We do know that ICT and information or knowledge society had promised a new democracy and a new social equality. But, in fact, they created new ways of inequality and exclusion, inside the dominant (developed) countries but also, especially, in developing (subordinated) countries.

Capitalism is always trying to take the public goods as private goods and services, in other words, has tried an expropriation of what is "common". What we need to do from the BOP is to invent or create a new way to think "the common" in our information (post-modern) societies, where to produce means to build in cooperation in cooperative communities. In this sense, the question of the access to goods and services for poor people is not only the main point. Instead we have to think whether we really do need everything to consume, and if every thing (goods or services) require producing, posing and using exclusively. We need a community that produce, reproduce and define itself. Again the ghost of Marx, through Derrida debts is here. 


\section{CONCLUSION WITHOUT CLOSING}

Overall economizing vs. de-construction of the language of economizing? That is the strategic question for the ICT people. The "conclusion" from our search for a justified cause for ICT in a landscape of economics and culture - of course - would take the form of dilemmas that calls for choices to be made.

- The fact that the contemporary capitalism promote inequalities and exclusions, it seems eternal through control. We suggest a political information economy that surpasses the incapacity of rational and instrumental policies and avoid putting communication in every day life in opposition to the economy and the material development of societies, i.e. as a kind of opposition between public life and private life. The social learning cycle then will have to recognize both levels in each one of its six phases.

- We have suggested ways of de-constructing the language (market, consumer, ICT) and de-sign for innovation working from the Bottom of the Pyramid: It forces us to innovate, not claim rights to impose our solutions upon other's cultural logic. We need to build a new confidence, spreading the possibilities of praxis and experience. But trust insists on leaving part of the initiative to an "other", it means to accept that the future can be in the action of an "other" (in the bottom, on the top, in one side of the pyramid or diamond). It implies a risk, a risk to renounce power and build spaces where "others" can be subjects of decisions and praxis.

- An important part of this de-construction works through the ICT. If we decide that what produces the affective work are social networks, community forms, then we can imagine that the instrumental action of the economic production could be united to the communicative action of the human relations. In this case the communication has not become impoverished, but the production has become enriched with the level of the human complexity. There is a possibility created by ICT and cyberspace which promote the creation of networked cultures without the fixed and homogenized identities assumed by the mass media; they also foster new routes for the circulation of ideas (not subject to centralized controls), the irruption of sub-cultures aware of the need to re-invent social and political orders, and a space for inter-cultural exchange and for the construction of shared artistic and political strategies. Then we are talking about micropolitics for the production of local knowledge made possible by the "fluid architecture" of cyberspace, emphasizing the "molecular" (as opposed to molar or characterized by large, 
homogeneous aggregates) nature of cyberspace. These micropolitics consist of practices of mixing, reusing, and recombination of knowledge and information.

- After de-constructing the pyramid and revising the diamond into the ISpace, we need to de-sign concepts, experiences and actions as diamonds of our time, given quality, time and space to the new epistemology and ontology that offered ICT to us. It would have to unite our cooperative work translated into community projects, using the social dialogue.

We must be asked what world we are de-signing; and we must be asked in what kind of world we want to live. We must look for answers that allow the incarnation of the voice of people (not the voice of others), the production and distribution of value for all (in a creative and cooperative action) and the liberation of the societies (in power-free communication).

\section{REFERENCES}

Boisot, Max (1995), Information Space, Routledge, London

Boisot, Max (1998), Knowledge Assets, Oxford University Press, New York

Coase, Ronald (1937): The Nature of the Firm, Economica, NS, 4

Coase, Ronald, (1991) The Institutional Structure of Production, Nobel Prize Lecture, Stockholm

Derrida, Jacques (1986), De la gramatología. México: Ed. Siglo XXI, 4a . Ed.

Derrida, Jacques (1998), Espectros de Marx. El estado de la deuda, el trabajo del duelo y la nueva internacional. Madrid: Ed. Trotta. English version in: http://www.marxists.org/reference/subject/philosophy/works/fr/derrida2.htm Original source: Specters of Marx, the state of the debt, the Work of Mourning, \& the New International, translated by Peggy Kamuf, Routledge 1994

Fischer, Edward F. (2001), Cultural Logics \& Global Economics, University of Texas Press

Hammel, G.; Prahalad, C.K. (1989), Strategic Intent, Harvard Business Review, Boston, May-June

Hardt Michael; Negri Antoni (2003), Imperio, Buenos Aires: Paidós.

Negri, Antonio (2003), time for revolution, Continuum, London

Ozbekhan, Hazan (1976), The predicament of mankind in C.W.Churchman \& R. Mason (eds.): World Modelling: A Dialogue, North-Holland American Elsevier, 1976

C.K.Prahalad, C.K.; Stuart Hart: The Fortune at the Bottom of the Pyramid, Strategy + Business, Issue 26

Prahalad, C.K. (2005), The Fortune from the Bottom of the Pyramid, Wharton School Publishing, Wupper Saddle River, NJ

Williamson, O.E. (1991), The Economic Institutions of Capitalism: Frims, Markets and Rational Contracting, The Free Press, New York

Williamson, O.E. (1991), The Logic of Economic Organization, in O.E.Williamson and S. Winter (eds.) The Nature of the Firm: Origins, Evolution and Development, Oxford University Press, New York 